\title{
HES5 silencing is an early and recurrent change in prostate tumourigenesis
}

\author{
Charles E Massie', Inmaculada Spiteri', Helen Ross-Adams', Hayley Luxton', \\ Jonathan Kay', Hayley C Whitaker', Mark J Dunning', Alastair D Lamb ${ }^{1,6,7}$, \\ Antonio Ramos-Montoya', Daniel S Brewer ${ }^{3}$, Colin S Cooper ${ }^{2,3}$, Rosalind Eeles ${ }^{2,4}$, \\ UK Prostate ICGC Group ${ }^{\dagger}$, Anne Y Warren ${ }^{5}$, Simon Tavaré1, David E Neal ${ }^{1,6,7}$ \\ and Andy G Lynch' \\ ${ }^{1}$ Cancer Research UK Cambridge Institute, University of Cambridge, Cambridge, CB2 ORE, UK \\ ${ }^{2}$ Division of Genetics and Epidemiology, The Institute of Cancer Research, Sutton, UK \\ ${ }^{3}$ Department of Biological Sciences and School of Medicine, University of East Anglia, Norwich, UK \\ ${ }^{4}$ Royal Marsden NHS Foundation Trust, London and Sutton, UK \\ Departments of ${ }^{5}$ Pathology, ${ }^{6}$ Urology and ${ }^{7}$ Surgical Oncology, Addenbrooke's Hospital, Hills Road, Cambridge, UK \\ ${ }^{\dagger}$ Group participants are listed in the supplementary materials
}

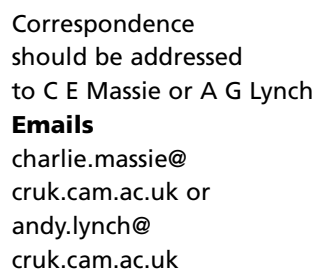

\begin{abstract}
Prostate cancer is the most common cancer in men, resulting in over 10000 deaths/year in the UK. Sequencing and copy number analysis of primary tumours has revealed heterogeneity within tumours and an absence of recurrent founder mutations, consistent with non-genetic disease initiating events. Using methylation profiling in a series of multifocal prostate tumours, we identify promoter methylation of the transcription factor HES5 as an early event in prostate tumourigenesis. We confirm that this epigenetic alteration occurs in $86-97 \%$ of cases in two independent prostate cancer cohorts ( $n=49$ and $n=39$ tumour-normal pairs). Treatment of prostate cancer cells with the demethylating agent 5-aza-2'-deoxycytidine increased HES5 expression and downregulated its transcriptional target HES6, consistent with functional silencing of the HES5 gene in prostate cancer. Finally, we identify and test a transcriptional module involving the AR, ERG, HES1 and HES6 and propose a model for the impact of HES5 silencing on tumourigenesis as a starting point for future functional studies.
\end{abstract}
Key Words
- prostate cancer
- epigenetics
- methylation
- HES5
- HES6
- AR
- ERG
- $\mathrm{NOTCH}$

\section{Introduction}

Current analysis of cancer genome sequencing has revealed disease processes and genomic alterations that may underlie disease initiation or evolution (Nik-Zainal et al. 2012, Baca et al. 2013, Tarpey et al. 2013). These approaches have identified and enumerated recurrently mutated driver genes in several cancer types, such as KRAS which is mutated in 93\% of pancreatic cancers (Biankin et al. 2012) and TP53 which is mutated in 96\% of highgrade serous ovarian cancers (Cancer Genome Atlas Research Network 2011), 69\% of oesophageal cancer (Weaver et al. 2014) and over 50\% of colorectal cancers (Cancer Genome Atlas Network 2012). In contrast with these highly recurrent mutations, a recent study of 112 aggressive primary prostate cancers has reported that the 
most significantly mutated gene (SPOP) was altered in only $13 \%$ of cases, with the next most commonly affected gene TP53 affected in only 6\% of prostate tumours (Barbieri et al. 2012).

Therefore, while genome sequencing approaches have provided important insights into the biology of prostate cancer (Berger et al. 2011, Baca et al. 2013, Lindberg et al. 2013, Weischenfeldt et al. 2013) the high intra- and intertumour heterogeneity coupled with the small samples sizes may have limited the identification of genetic driver events in primary tumours. Indeed, previous genome sequencing studies have reported few common mutations between different tumour foci within the same prostate (Lindberg et al. 2013), highlighting marked intra-tumour heterogeneity and the absence of a genetic founder mutation. This complexity has led many groups to focus on late-stage, aggressive disease with the aim of identifying genomic events associated with disease progression (Barbieri et al. 2012, Grasso et al. 2012). However, their remain important unanswered questions over the early stages of prostate tumour evolution where genetic events appear to be for the most part heterogeneous. One notable exception to this is gene fusions involving ETS (E26 transformation-specific) transcription factors that have been found to occur in approximately half of all prostate cancers (Tomlins et al. 2005, Perner et al. 2006). However, these androgen receptor $(A R)$-driven gene fusions alone are insufficient to initiate prostate tumours in disease models (Carver et al. 2009, Chen et al. 2013) and may not be early 'founder' events in disease evolution (Barry et al. 2007, Mertz et al. 2013, Minner et al. 2013).

Therefore current evidence would seem to suggest that if a common initiating driver event exists it is not genetic, implicating other mechanisms in disease aetiology. In addition to somatic mutation several other disease-initiating pathways have been proposed in prostate cancer including germline predisposition (Kote-Jarai et al. 2011, Eeles et al. 2013), telomere shortening (Sommerfeld et al. 1996, Heaphy et al. 2013), chronic inflammation (Elkahwaji et al. 2009, Caini et al. 2014), metabolic stress (Freedland 2005, Kalaany \& Sabatini 2009) and epigenetic alterations (Lee et al. 1994, Kanwal et al. 2014). It is likely that non-genetic and genetic alterations interact during tumourigenesis and several studies have identified interactions between somatic mutations and micro-environmental changes (Garcia et al. 2014), inflammation (Kwon et al. 2014) and metabolism (Kalaany \& Sabatini 2009). Current technologies allow accurate identification and quantification of epigenetic alterations and are therefore a tractable second line of enquiry to identify driver events in prostate tumourigenesis.

We have recently identified a role for the enhancer of split transcription factor HES6 in prostate cancer and AR signalling (Ramos-Montoya et al. 2014). Herein, we characterise an epigenetic alteration at the promoter of the related HES5 gene, which has been recently reported in a panel of genes that showed promise as a prostate cancer marker in biopsy samples (Paziewska et al. 2014). We profile this change in detail and show it to be an early event in prostate cancer development and highly recurrent across three unrelated prostate tumour cohorts. We then characterise an interaction between the epigenetic silencing of HES5 and the expression of HES6 and provide evidence for interactions with known oncogenic pathways in prostate cancer (namely AR signalling and $E R G$ gene fusions), highlighting a transcriptional network that is altered in prostate cancer development first by an epigenetic change and then by a genomic rearrangement.

\section{Materials and methods}

\section{Sample cohorts}

In a series of four radical prostatectomy specimens, we systematically dissected the whole prostates, identified regions containing tumour and harvested 17 tumour-rich samples from 13 spatially separated tumour cores (median $46 \%$ tumour, interquartile range (IQR) 36-62\%), four adjacent benign samples and three whole-blood samples (Fig. 1a and Supplementary Figure 1a, see section on supplementary data given at the end of this article). Each tumour core was taken from a $5 \mathrm{~mm}$ tissue slice and the tumour content of samples used for DNA extraction was assessed by a pathologist using H\&E staining of immediately adjacent sections (Warren et al. 2013). From two such cores, we also took three sets of sections for DNA extraction to allow assessment of heterogeneity within cores in addition to the spatial heterogeneity within and between cancerous prostates (Supplementary Figure 1a). These samples were used for global methylation profiling using Infinium HumanMethylation450 arrays (see below for details).

In a separate cohort of 39 matched prostate tumour and adjacent benign samples, we performed targeted bisulphite sequencing of the HES5 promoter, to assess the frequency of HES5 hypermethylation in prostate cancer. This analysis provides a promoter-wide view of DNA methylation changes at the HES5 promoter (in contrast to the limited number of CpGs assessed using methylation profiling arrays).

Published by Bioscientifica Ltd. 
A

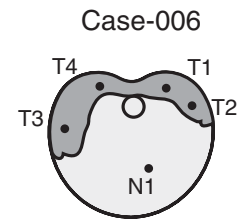

B

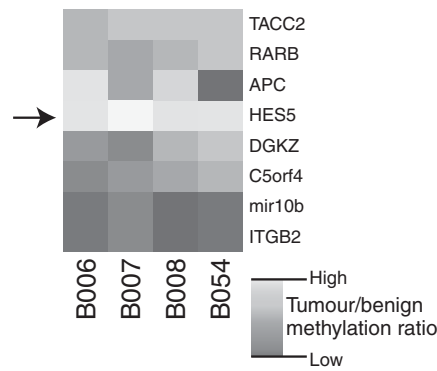

Case-007

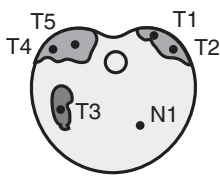

C
Case-008

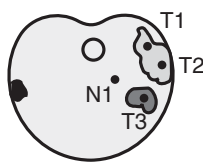

Case-006 Case-007

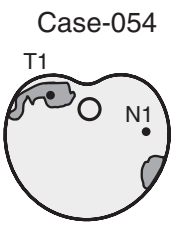

Case-008 Case-054

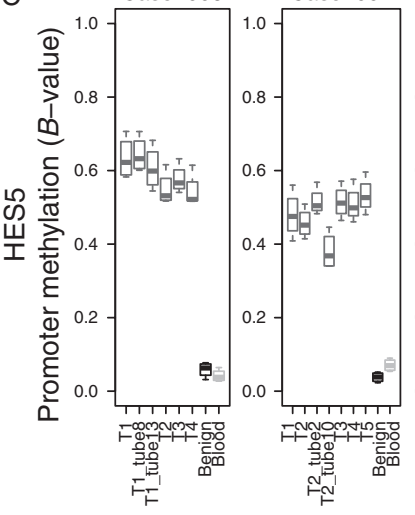

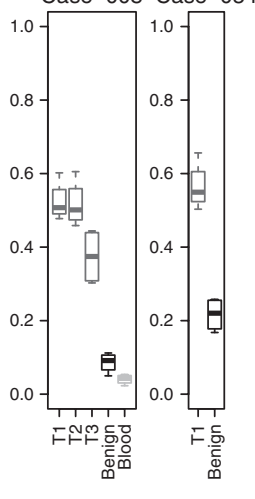

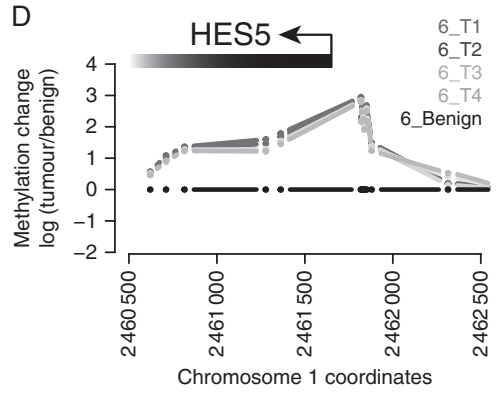

E

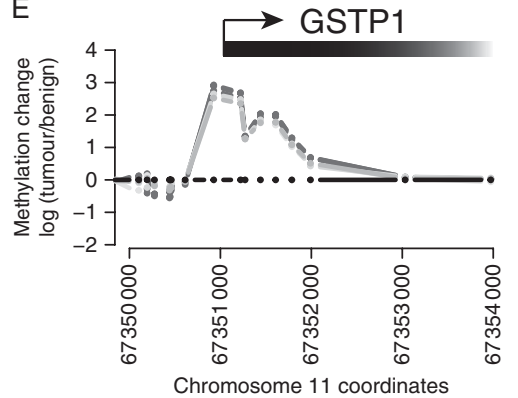

\section{Figure 1}

HES5 promoter methylation is an early event in prostate tumourigenesis. (A) Representation of sections through four cancerous prostates from which multiple tumour cores (T1-T5) and adjacent benign cores (N1) were taken for methylation analysis. Regions in purple indicate histologically malignant foci and different shades of purple indicate tumour foci that appeared unconnected in 3D-sectioning. Sample keys provided are ICGC Prostate UK IDs. (B) Heatmap showing the median tumour over benign methylation changes at regions in the promoter regions of eight candidate genes. (C) Boxplots showing the methylation status at the promoter region of HES5 in the cohort of prostate tumours with multiple tissue cores,

In an unrelated, larger cohort of prostate cancers with publicly available methylation array data $(n=304$ tumours, $n=49$ matched normal samples) (Weinstein et al. 2013), we assessed the recurrence of HES5 promoter methylation.

\section{DNA methylation profiling in blood, benign prostate and multiple spatially separate tumour foci}

Clinical samples for analysis were collected from prostatectomy patients with full research consent at the Addenbrooke's Hospital, Cambridge, UK. The prostates were sliced and processed as described previously (Warren et al. 2013). A single $5 \mathrm{~mm}$ slice of the prostate was selected for research purposes. Tissue cores of $4 \mathrm{~mm}$ or $6 \mathrm{~mm}$ were taken from the slice and frozen. The frozen cores were mounted vertically and sectioned transversely giving a single $5 \mu \mathrm{m}$ frozen section for H\&E staining followed by $6 \times 50 \mu \mathrm{m}$ sections for DNA preparation using the Qiagen Allprep kit. Using the Infinium HumanMethylation 450 BeadChip kit, DNA was subjected to bisulphite adjacent benign and blood DNA samples. Boxplots depict quartiles for probes within promoter region genomic windows, error bars denote $95 \% \mathrm{Cl}$ and data points are shown for values outside $95 \% \mathrm{Cls}$. (D and $\mathrm{E}$ ) Genomic views of DNA methylation in tumour cores compared with adjacent benign tissue for (D) the HES5 gene promoter region and (E) the methylation-positive control GSTP1 gene promoter. Plots show the methylation profiles from multiple tumour foci for Case-006, data are presented as $\log _{2}$ ratio of tumour over benign. Gene promoters and orientation are annotated at the top of each plot.

conversion, amplification, fragmentation, hybridisation, extension and labelling, according to the manufacturer's instructions (Illumina, Little Chesterford, Essex, UK). Bead summary data from Infinium HumanMethylation450 arrays were processed using the Minfi package in the $\mathrm{R}$ statistical software (Aryee et al. 2014, R-Core-Team 2014). As previously described, probe types were normalised separately (Marabita et al. 2013) before generating $M$ - and $B$-values for exploratory analysis. Summary plots were generated in the R statistical software (R-Core-Team 2014). Raw and processed data have been uploaded to the ArrayExpress portal under accession E-MTAB-2964, in addition all code used to generate figures in the paper are included as part of the R-markdown HTML document available on our group webpage.

\section{Targeted bisulphite sequencing}

PCR primers were designed to amplify a $441 \mathrm{bp}$ fragment from the HES5 promoter containing $60 \mathrm{CpGs}$ (HES5BSx-F: 5'-GAGGGGGTGTTAGGTTGGTT-3'; HES5-BSx-R:

Published by Bioscientifica Ltd 
$5^{\prime}$-ACCCACCTACTCCTTAAAAAAC-3'). The amplicons were generated separately for 39 matched tumour normal sample pairs and assessed before preparing barcoded sequencing libraries using a Nextera XT kit (Illumina). Barcoded DNAs were quantified and equal amounts of each indexed library were then pooled and sequenced on an Illumina MiSeq (PE300). Fastq data files were split using index sequences and downstream methylation analysis was performed using Bismark (Krueger \& Andrews 2011) and summary plots and test statistics were generated using the R statistical software (R-Core-Team 2014). This analysis gave a median sequencing coverage of $786 \times$ (Supplementary Figure 3 , see section on supplementary data given at the end of this article). All code used to generate figures in the paper are included as part of the R-markdown HTML document available on our group webpage.

\section{Data mining}

An R markdown document containing all code required to reproduce our analysis and all figures has been included as a supplementary HTML document (available on our group webpage). Briefly, DNA methylation 450k array data for LNCaP prostate cancer cells and PrEC benign prostate epithelial cells (CC-2555, Lonza, Basel, Switzerland) were obtained from GEO (triplicate data for each cell line from GSE34340 and singleton data for each cell line from GSE40699) (Statham et al. 2012, Varley et al. 2013) and summary plots were generated using the $\mathrm{R}$ statistical software (R-Core-Team 2014). Gene expression data from LNCaP cells treated with the demethylating agent 5-aza2 '-deoxycytidine were retrieved from GEO (GSE25346). Gene expression data from human prostate benign and tumour tissues were obtained from GEO (GSE3325). Gene expression data from control and ERG-knockdown VCaP cells was retrieved from GEO (GSE60771). All GEO data were retrieved using the GEOquery package in the $\mathrm{R}$ statistical software and summary plots were generated using the same software (Davis \& Meltzer 2007, R-Core-Team 2014). Transcriptional networks were drawn using the BioTapestry application (Longabaugh 2012) constructing models using ChIP-seq binding profiles, expression correlations and published transcriptional links.

\section{HES5 motif enrichment analysis}

The position weight matrix for HES5 was obtained from Yan et al. (2013) and used to search the genomic sequence of the HES6 gene locus (including $1 \mathrm{~kb}$ upstream and $1 \mathrm{~kb}$ downstream sequence). Motif searches were carried out using the
RSAT matrix-scan (with human 'upstream-noorf' background control) (Turatsinze et al. 2008), and motif scores were visualised using BioSAVE (Pollock \& Adryan 2008).

\section{Androgen time-course gene expression profiling in LNCaP and VCaP cells}

Following 72-h steroid depletion in the media containing $10 \%$ charcoal-stripped FBS, LNCaP and VCaP cells were subjected to androgen stimulation (1 nM R1881) or vehicle control treatment $(0.01 \%$ ethanol). The cells were harvested at the indicated timepoints over a $24 \mathrm{~h}$ period following treatment and RNA extracted using Trizol (Life Technologies). For the LNCaP treatment time-course, a full analysis has been published (Massie et al. 2011) and raw and normalised data have been deposited at GEO (GSE18684). Data for the VCaP androgen treatment time-course have also been deposited at ArrayExpress (E-MTAB-2968). Expression data were analysed using the beadarray software, with spatial artefacts identified and removed automatically (BASH) and curated manually (Dunning et al. 2007, Cairns et al. 2008). The resulting data set was summarised with outliers removed to obtain mean log-intensity and standard error for each probe/array combination.

\section{Results}

\section{HES5 promoter methylation is an early event in prostate tumourigenesis}

In order to investigate the epigenetic landscape within and between prostate tumours, we systematically dissected four radical prostatectomy specimens, harvesting 17 tumour-rich samples from 13 spatially separated tumour cores (median 46\% tumour, IQR 36-62\%), four adjacent benign samples and three whole-blood samples (Fig. 1a and Supplementary Figure 1a). Consistent with previous reports (Lindberg et al. 2013), these spatially separated tumour cores appeared to be only distantly related by somatic mutations and therefore our aim was to identify early (common 'trunk') epigenetic events. Analysis of the methylation distributions for all assayed CpGs revealed that global methylation profiles were similar between tumour and benign prostate samples (Spearman's rank correlation of tumour vs benign methylation profiles 0.94-1.00; Supplementary Figure 1b,c, d and e). A recent study has highlighted eight genomic loci that showed differential methylation in a series of unmatched tumour and benign prostate samples (i.e. from

Published by Bioscientifica Ltd. 
different individuals), a subset of which were proposed as molecular markers to support pathological diagnosis of biopsies (Paziewska et al. 2014). We assessed the reproducibility and clonality of these eight differentially methylated regions in our cohort of cases with multiple spatially separate tumour samples, matched benign tissue and blood DNA samples (Fig. 1b and Supplementary Figure 1f, g, h, i, j, k, l, m).

In our cohort, the promoter region of the HES5 gene showed the largest and most consistent increase in methylation in tumour samples compared with matched normal tissue (median 7.6-fold increase, median variance $=$ 0.003), together with consistently low methylation in adjacent normal tissue (median normal methylation= 0.08 , median variance $=0.0006$; Fig. $1 \mathrm{~b}, \mathrm{c}, \mathrm{d}$ and Supplementary Figure 1f, g, h, i, j, k, l, m). The study by Paziewska et al. (2014) showed low HES5 promoter methylation in benign prostatic hyperplasia and hypermethylation in prostate tumour biopsies. Among the other regions examined, we found that tumour methylation at the ITGB2 and mir10B loci showed no difference with matched benign tissue, the APC locus showed variable differences between tumour and matched benign and the remaining four loci (RARB, C5orf4 (FAXDC2), TACC2 and $D G K Z$ ) showed increased methylation in tumour vs
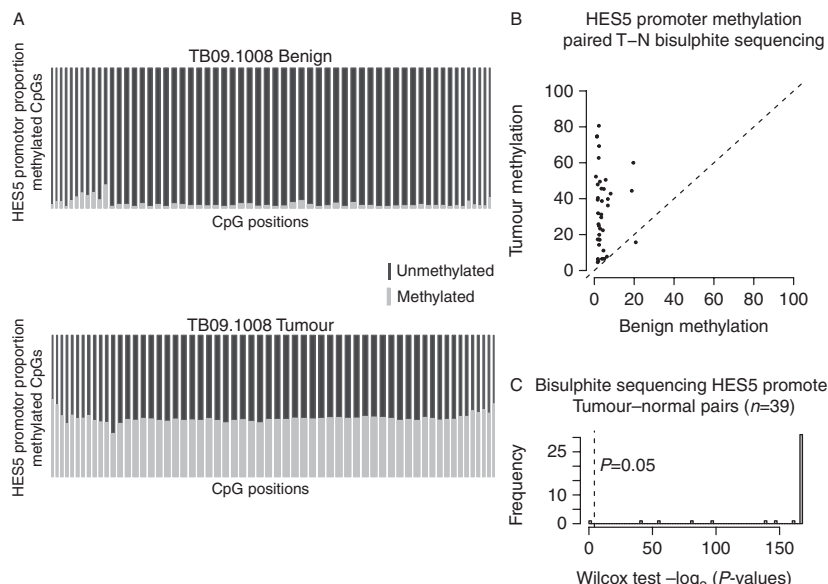

\section{Figure 2}

Validation of HES5 promoter methylation as a common event in two additional independent prostate cancer cohorts. (A) CpG methylation summary of the HES5 promoter as determined by bisulphite sequencing from a representative tumour-normal pair. Each column represents one CpG assayed $(n=60)$, red and blue stacked bars represent the proportion of methylated and unmethylated reads, respectively, at each CpG. Column widths are proportional to sequencing coverage (median $=786 \times$ ).

(B) Scatter plot summary of HES5 promoter methylation for 39 tumournormal pairs. (C) Histogram summary of significance testing for increased HES5 promoter methylation in tumour vs normal sample pairs $(n=39$ pairs matched benign samples, although to a lesser extent than the HES5 locus (Fig. 1b, c, d and Supplementary Figure 1f, g, h, i, j, k, 1, m). The tumour-specific methylation changes at the HES5 promoter were consistent within and between cases and comparable with the hypermethylation observed at the GSTP1 gene (Fig. 1d and e), which is invariably silenced in prostate cancer and has been extensively studied (Lee et al. 1994). These consistent methylation changes at the HES5 promoter appear to be locus specific, as highlighted by the similarity of global methylation profiles (Supplementary Figure 1b, c, d and e) and the absence of consistent changes in DNA methylation at other genomic loci across spatially separated tumour samples from the same patient (Supplementary Figure 2, see section on supplementary data given at the end of this article).

Therefore using our cohort of cases with multiple tumour foci and matched benign samples, we found that hypermethylation at the HES5 promoter region was observed across tumour samples from all patients and in all spatially separated tumour foci from the same patient. The homogenous hypermethylation of the HES5 promoter across genetically heterogeneous tumour cores is consistent with this being an early event in tumourigenesis (Fig. 1c and Supplementary Figure 1m).

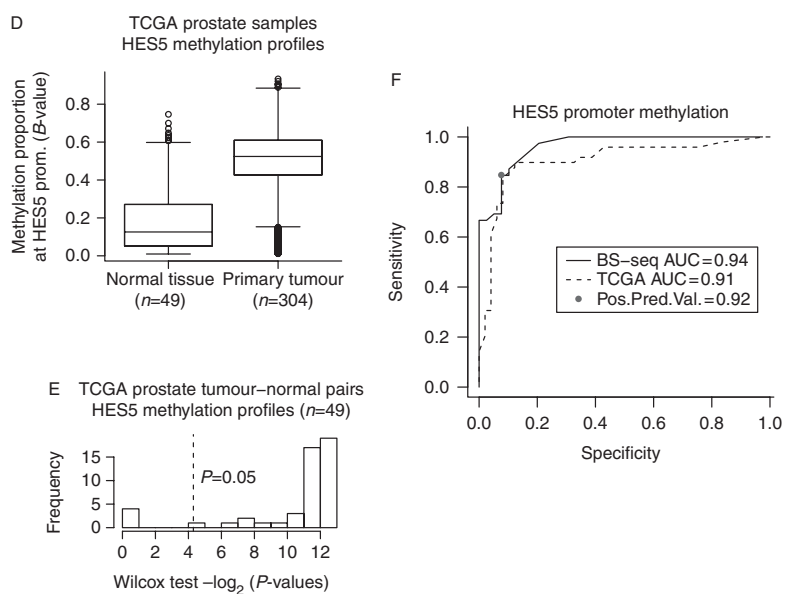

from panel-C; paired Wilcox rank sum test; $-\log _{2} P$ values are plotted to visualise distributions). (D) Boxplot summary of HES5 promoter methylation for 304 tumour and 49 benign prostate samples on Illumina 450k arrays (TCGA data). (E) Histogram summary of significance testing for increased HES5 promoter methylation in TCGA tumour vs normal sample pairs ( $n=49$ pairs from panel-E; paired Wilcox rank sum test; $-\log _{2} P$ values are plotted to visualise distributions). (F) ROC curve for HES5 promoter methylation using data from bisulphite sequencing of 39 tumour normal pairs ( $A, B$ and $C$ ) and methylation array profiling of 49 tumour normal pairs (D and $E$ ).

Published by Bioscientifica Ltd. 


\section{HES5 promoter methylation is a recurrent event in prostate tumours}

To assess the frequency of HES5 hypermethylation in prostate cancer, we performed targeted bisulphite sequencing of the HES5 promoter in a separate cohort of 39 matched tumour and adjacent benign samples. This analysis included $60 \mathrm{CpGs}$ in the HES5 promoter and gave a median sequencing coverage of $786 \times$ (Supplementary Figure 3). This analysis provided a comprehensive view of DNA methylation across the HES5 gene promoter, in
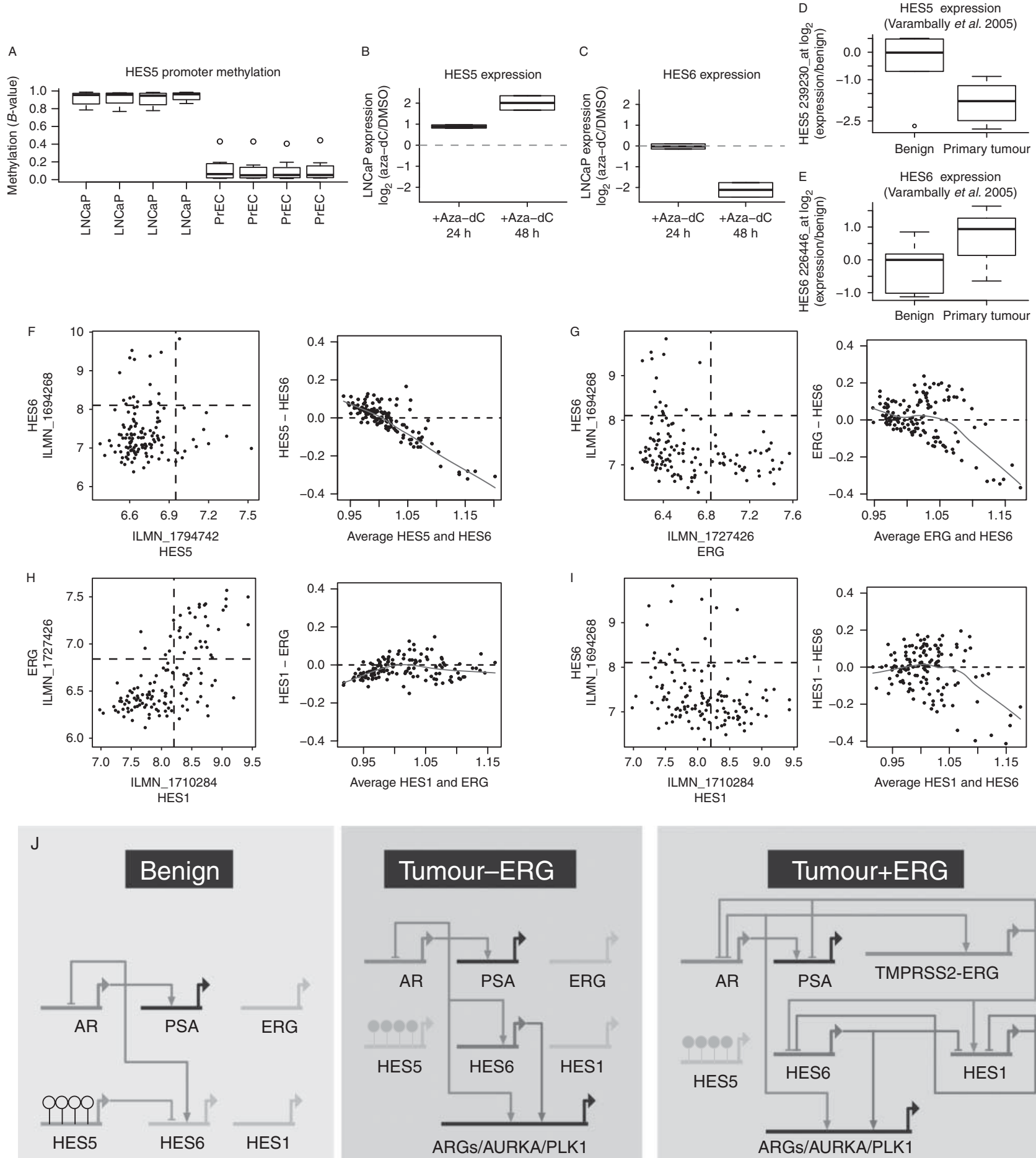

Tumour-ERG
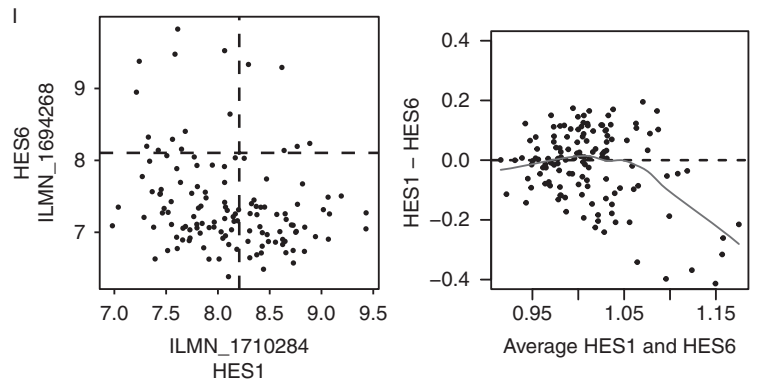

HES1

Average HES1 and HES6
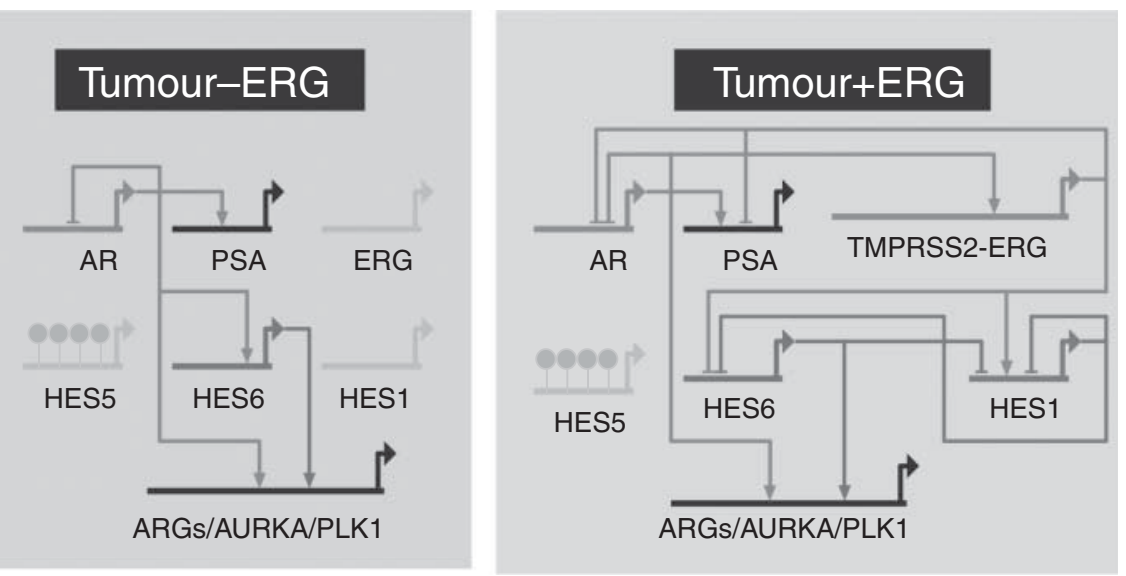
contrast to the four CpGs assessed using methylation arrays and a narrow genomic window in a previous study (Paziewska et al. 2014). Benign samples showed hypomethylation across the entire HES5 promoter, whereas matched tumour samples had consistent hypermethylation across all 60 CpGs assayed (Fig. 2a, b and Supplementary Figure 4, see section on supplementary data given at the end of this article). This pattern of hypomethylation in benign tissue and hypermethylation in tumours was consistent in 38/39 matched tumour normal pairs $(97 \%$ at $P<0.05$, Wilcox test; Fig. 2c). In the single discordant sample pair, there was increased methylation in the matched benign sample that was maintained in the tumour (median methylation 20.7 and 15.4 respectively; Supplementary Figure 4), consistent with either a pre-transformation change in this single case or tumour contamination of this normal tissue core.

We also assessed HES5 methylation in an additional prostate cancer patient cohort using publicly available methylation array data ( $n=304$ tumours, $n=49$ matched normal samples) (Weinstein et al. 2013). In this second validation cohort, we again observed hypermethylation in tumours and hypomethylation in benign samples (42/49 pairs, $86 \%$ at $P<0.05$, Wilcox test; Fig. $2 \mathrm{~d}$ and e). Receiver operating characteristic (ROC) curve analysis for these two geographically distinct validation cohorts run on different platforms revealed high sensitivity and specificity (positive predictive value $(\mathrm{PPV})=0.92$, area under the curve (AUC) $>0.9$, Fig. 2f). These results clearly demonstrate that in addition to being an early event in prostate tumourigenesis HES5 methylation is a highly recurrent event in prostate cancer, suggesting potential as a specific disease marker and an early acquired (or selected) event in prostate tumourigenesis.

\section{HES5 is silenced in prostate cancer cells and demethylation restores expression}

Consistent with observations in human tumours, we found that LNCaP prostate cancer cells exhibit hypermethylation of the HES5 promoter, in contrast to HES5 hypomethylation in benign epithelial cells PrEC (Fig. 3a). The expression of HES5 is low or undetectable in cultured prostate cancer cell lines and is also low in human prostate tumours (Supplementary Figure 5a, c, see section on supplementary data given at the end of this article and Fig. 3d, f), consistent with epigenetic silencing of HES5 in prostate cancer (Supplementary Figure $5 \mathrm{~g}$ and $\mathrm{h}$ ). Treatment of LNCaP cells with the DNA demethylating agent 5-aza-2'-deoxycytidine caused de-repression of the HES5 gene (Fig. 3b), consistent with active epigenetic silencing of the HES5 gene in prostate cancer cells.

\section{HES5 epigenetic silencing is associated with HES6 expression}

HES5 is known to play a role similar to that of HES1 in developmental processes (Hatakeyama et al. 2004, 2006, Tateya et al. 2011), and both are involved in negative feedback loops with HES6 (Fior \& Henrique 2005, Jacobsen et al. 2008), which antagonises the activity of HES1 and HES5 (Bae et al. 2000, Salama-Cohen et al. 2005). Of note, HES6 has been recently reported to play an important functional role in prostate cancer enhancing oncogenic signalling through the $A R$ (Ramos-Montoya et al. 2014). Although a rare HES6 gene fusion has been reported (Annala et al. 2014), no molecular mechanism has been found for the frequent up-regulation of HES6 in prostate cancer. In prostate cancer cells, de-repression of HES5 with the demethylating agent 5-aza-2'-deoxycytidine resulted

\section{Figure 3}

HES5 expression is repressed by methylation in prostate tumour cells and shows an inverse trend with HES6 expression. (A) Boxplot showing methylation status of the HES5 promoter region in LNCaP prostate cancer cells and PrEC benign prostate cells (triplicates from GSE34340 and singletons from GSE40699). (B and C) Expression of (B) HES5 and (C) HES6 in LNCaP prostate cancer cells treated with the demethylating agent 5-aza$2^{\prime}$-deoxycytidine (Aza-dC) for 24 and 48 h (GSE25346). Expression presented as $\log _{2}$ ratios over control untreated cells. (D and E) Boxplot showing the expression of (D) HES5 and its known target (E) HES6 in a separate cohort of prostatic benign and primary tumour tissue (GSE3325). Boxplots depict quartiles, error bars denote $95 \% \mathrm{Cl}$ and data points are shown for values outside $95 \%$ Cls. (F, G, H and I) Scatter plots of gene expression from clinical prostate tumours showing the relationship between (F) HES5 and HES6, (G) HES6 and ERG, (H) HES1 and ERG, (I) HES1 and HES6 (including samples from the cohort shown in Fig. $2 b$ and $c$ ). Plots on the left show pairwise relationships between gene expression, dashed quadrant lines indicates the mid-point of expression values for each gene. Plots on the right show the relationship between the level and difference in expression for each pair of genes (using median centred values for each gene). Divergence from the dashed zero line indicates an inverse relationship, red trend lines depict loess regression. (J) Simple models of the putative expression networks in benign prostate, prostate cancer and ERG-positive prostate cancer involving the AR, HES5, HES6, ERG and HES1. Genes are depicted by thick horizontal lines, connecting lines depict transcriptional targets of each encoded transcription factor. Connectors with arrowheads depict positively regulated targets, while connectors with flat ends depict repressed targets. Genes shown in grey depict low/no expression in a given condition. On the HES5 gene open circles depict hypomethylation and filled circles depict hypermethylation. ARGs denotes AR-regulated genes. Model drawn using BioTapestry.

Published by Bioscientifica Ltd. 
in a delayed downregulation of HES6 (Fig. 3c), consistent with HES5 repression of HES6. We also observed an inverse relationship between HES5 and HES6 expression in a series of primary tumours compared with benign prostate
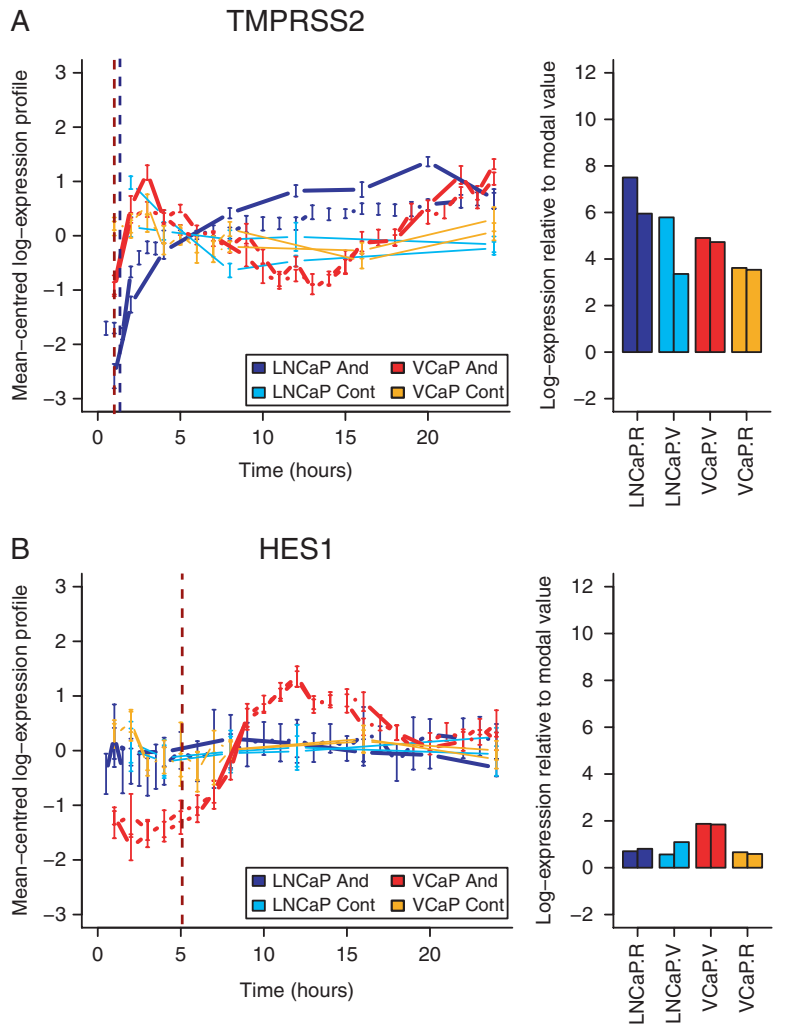

$\mathrm{F}$

$$
20 \mathrm{~kb}
$$

chr3: $195330000,195340000,195350000$

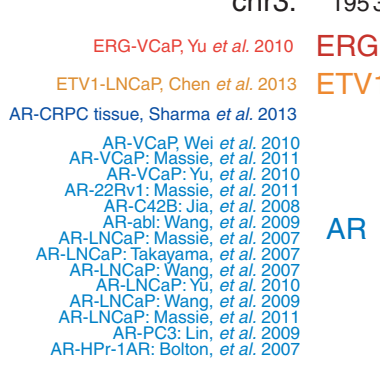

AR samples, where HES5 expression decreased and HES6 expression increased in tumour vs benign prostate samples (Fig. 3d and e). In our cohort of multiple spatially separated tumour samples, we found that HES5 expression
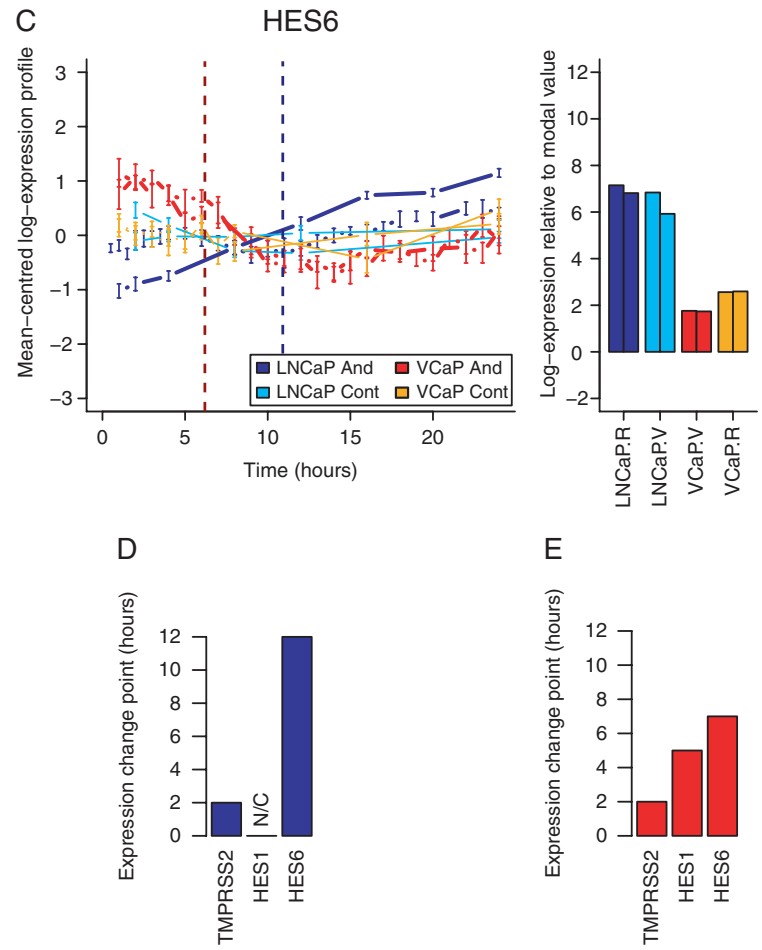

$\mathrm{H}$

ERG

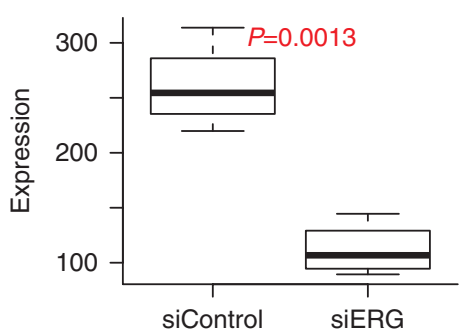

I

HES 1

G

$5 \mathrm{~kb}$

HES1

chr2: $\quad 238813000 \quad 238815000 \quad 238817000 \quad 238819000$
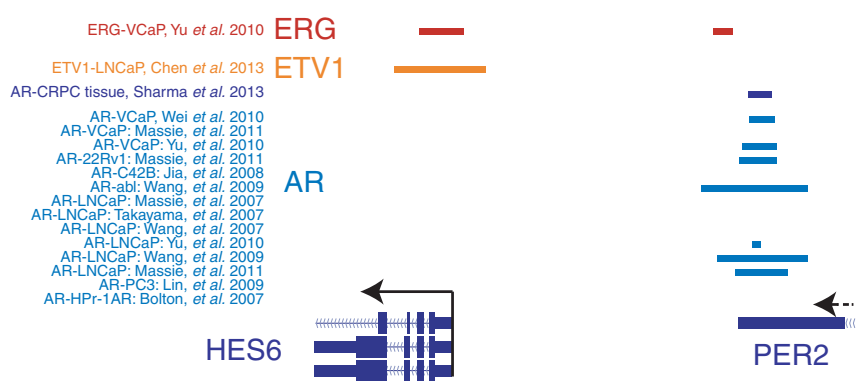
was decreased in tumour cores compared with matched benign tissue and that HES6 was also increased in some of those tumour cores, consistent with HES5 silencing in tumourigenesis and additional mechanisms regulating HES6 expression (Supplementary Figure 5e and f). However, we found no evidence of a correlation between HES5 methylation and expression in a larger series of tumours $(n=39)$, nor between HES5 and HES6 expression in this tumour cohort (Fig. 3f). This lack of correlation may at least in part be explained by the low or absent expression of HES5 in prostate tumour samples (Figs 2 and $3 \mathrm{~d}, \mathrm{f})$ confounding such correlative analysis. Indeed, we found that HES5 expression appeared to be low and showed little variation in this series of 39 prostate tumours (Fig. 3f). The few samples that had slightly higher HES5 expression also had low HES6 expression (Fig. 3f), which although not compelling alone is consistent with our other data supporting an inverse relationship between HES5 5 and HES6 in addition to highlighting the recurrent silencing of HES5 in tumourigenesis. There are no successful HES5 genomic binding data nor chromatin immunoprecipitation grade antibodies for HES5; therefore; we could not assess direct binding of HES5 at the HES6 gene locus (Yan et al. 2013). However, the preferred consensus DNA-binding sequence of HES5 has been determined experimentally (Yan et al. 2013) and we found strong HES5 consensus sites in and around the HES6 gene (Supplementary Figure 5i, $\mathrm{j}$ and k). Taken together our observations of i) the inverse correlation between HES5 5 and HES6 in cancer cells treated with 5 -aza-2'-deoxycytidine, ii) their inverse correlation in tumour-normal comparisons and iii) strong consensus HES5 binding sites at the HES6 gene locus suggests that HES5 may repress HES6 in prostate epithelial cells. The ubiquitous HES5 silencing in tumours cells may therefore potentiate (or de-repress) HES6 expression in prostate tumours.

\section{ERG and HES6 expression show an inverse relationship}

Despite the early and frequent silencing of HES5 in prostate cancer, we observed variable expression of the HES5 transcriptional target HES6 in prostate tumour samples (Fior \& Henrique 2005) (Fig. 3f and Supplementary Figure 5f), prompting us to investigate other factors that may regulate HES6 expression in prostate tumour cells. We found that variations in HES6 expression showed an inverse relationship with expression of the frequently rearranged $E R G$ gene in prostate tumours, highlighted by an inverse correlation $(r=-0.28)$ and mutual exclusivity of HES6 and $E R G$ expression (i.e. no samples have both high $E R G$ and HES6 expression, Fig. $3 g$ left panel). This inverse relationship is illustrated clearly by the increasing difference between ERG and HES6 at higher levels of expression (i.e. divergence from zero with increasing expression, Fig. $3 \mathrm{~g}$ right panel).

\section{ERG and HES1 expression show a positive correlation}

In contrast the other major HES6 antagonist HES1 (Bae et al. 2000, Hatakeyama et al. 2004, 2006, Jacobsen et al. 2008) showed a strong positive correlation with $E R G$ expression ( $r=0.65$; Fig. $3 \mathrm{~h}$ ), suggesting an ERG-HES1HES6 transcriptional network in $E R G$-fusion positive prostate cancer cells (Fig. $3 \mathrm{~g}, \mathrm{~h}$ and $\mathrm{i}$ ). In support of this prediction, we found evidence for extensive $E R G$ binding at the HES1 gene locus (Fig. 4f) and also confirmed the previously reported AR binding sites upstream of the HES6 gene (Ramos-Montoya et al. 2014) by using multiple data sets (Fig. 4g).

\section{Figure 4}

Detailed gene expression time-course analysis, genomic binding profiles and $E R G$ knockdown supports an $A R-E R G-H E S 1-H E S 6$ transcriptional cascade. (A, B and C) Gene expression profiles from androgen stimulation and vehicle control time-course experiments using VCaP (ERG-positive) and LNCaP (ERG-negative) prostate cancer cells. Panels on the left show the mean centered transcript profiles (as $\log _{2}$ ratios/average) and panels on the right show bar plots of the expression levels $\left(\log _{2}\right.$ intensity) for (A) TMPRSS2, (B) HES1 and (C) HES6. Error bars depict $\mathrm{Cl}$ for each time-point measured. Vertical dashed lines correspond to the 'change-points' for gene expression in the VCaP (dark red) and LNCaP (dark blue) time-series. ( $D$ and E) Bar plots showing the androgen-induced expression 'change-points' for each gene from (D) LNCaP and (E) VCaP androgen treatment time-series (values correspond to the dashed lines in panels $A, B$ and $C$ ). ( $F$ and $G$ )
Genomic binding profiles for ERG, ETV1 and the $A R$ in prostate cells at the (F) HES1 and (G) HES6 gene loci. Genomic binding sites for each transcription factor are depicted by coloured horizontal rectangles. Multiple datasets are included for $A R$-binding profiles using the labelling scheme 'factor-sample, study' (i.e. 'AR-VCaP, Wei et al. (2010)' represents the binding profile of the AR in VCaP cells from the study of Wei et al. (2010)). A scale bar is shown at the top together with chromosomal locations and gene locations and orientations are indicated at the bottom of each plot. ( $\mathrm{H}$ and I) Boxplots showing the expression of (H) ERG and (I) HES1 in VCaP cells under control or ERG knockdown conditions (GSE60771). Significance testing was performed using $t$-tests, $P$ values annotated on each plot. http://erc.endocrinology-journals.org DOI: $10.1530 /$ ERC-14-0454
(C) 2015 The authors Printed in Great Britain
Published by Bioscientifica Ltd. 


\section{A transcriptional network involving HES5, AR, ERG and HES6}

Combining our observations of HES5 silencing in prostate cancer with expression correlations in prostate tissue, DNA binding profiles for $E R G$ and the $A R$ and published transcriptional links (i.e. between HES5 and HES6 (Fior \& Henrique 2005), HES1 and HES6 (Jacobsen et al. 2008), reciprocal HES6 and HES1/5 negative-feedback (Bae et al. 2000, Salama-Cohen et al. 2005, Hatakeyama et al. 2006) and AR and HES6 (Ramos-Montoya et al. 2014)), we constructed models of putative gene expression networks in benign prostate, prostate cancer and prostate cancer harboring ERG-rearrangements (Fig. 3j). In this model, we predict that i) HES5 expression in benign epithelial cells contributes to HES6 repression and ii) HES5 promoter methylation and silencing in prostate tumours potentiates $A R$ activation of HES6 to start an oncogenic feed-forward transcriptional signalling network (Fig. 3j). Finally, our model suggests that in tumour cells harbouring an ERG gene fusion iii) $A R$ activation of the $E R G$ fusion gene creates a dynamic negative feedback loop impacting on both the AR and HES6, creating a more complex transcriptional network (Fig. 3j). Negative feedback loops are common motifs in biological networks and have been shown to increase robustness and speed-up response times of transcriptional circuits (Rosenfeld et al. 2002, Shen-Orr et al. 2002, Austin et al. 2006, Nevozhay et al. 2009). Therefore, our model may highlight a previously unknown signalling node in ERG-positive tumours that may increase the robustness and response-rates of key pathways in prostate cancer.

\section{ERG-fusion status affects HES1 and HES6 regulation by the AR}

We tested the putative AR-HES6 and AR-ERG-HES1-HES6 transcriptional networks in $A R$-positive prostate cancer cells with and without TMPRSS2-ERG gene fusions (VCaP and LNCaP, respectively; Fig. 4). Using an androgen stimulation time-course, we were able to both track changes in gene expression and map their dynamics in prostate cancer cells with and without $A R$-regulated $E R G$ fusion expression following $A R$ stimulation (Tomlins et al. 2005, Massie et al. 2011). We observed early up-regulation of the known AR-target gene TMPRSS2 in both ERG-fusion positive and $E R G$-fusion negative cells in response to androgen stimulation (Fig. 4a), while ERG induction only occurred in TMPRSS2-ERG fusion positive cells (Supplementary Figure $7 \mathrm{a}$, see section on supplementary data given at the end of this article). Consistent with its epigenetic silencing, we found low expression and no change in HES5 expression in either cell type (Supplementary Figure 7b). HES1 expression was not significantly changed in $E R G$-fusion negative cells, but showed strong androgen induction in ERG-fusion positive cells (Fig. 4b). HES6 expression was increased in ERG-fusion negative cells but was downregulated in ERG-fusion positive cells (Fig. 4c). Defining the timing of gene expression changes ('change-points') for these genes in ERG-fusion positive cells shows the sequence of events: i) TMPRSS2-ERG upregulation; ii) HES1 upregulation; iii) HES6 downregulation (Fig. 4e). These data show that HES1 is only induced by androgen signalling in ERG-fusion positive cells and that induction precedes HES6 repression. This transcriptional data are supported by genome-wide binding profiles showing that the AR is recruited to the HES6 gene locus (Fig. 4g) but not to the HES1 gene locus in ERG-fusion negative cells (Fig. 4f). However, in $E R G$-fusion positive cells, ERG binding is widespread at the HES1 locus (Fig. 4f), consistent with direct $E R G$ regulation of the HES1 gene.

\section{HES1 expression is dependent on ERG}

To test this further, we looked at the expression of HES1 following ERG knockdown in VCaP cells (Mounir et al. 2014) (Fig. 4h and Supplementary Figure 6b, c, see section on supplementary data given at the end of this article) and found that HES1 expression was dependent on the expression of $E R G$ (Fig. $4 \mathrm{i}$ and Supplementary Figure 6d, e), further supporting our model. In addition to the timing of expression changes in response to androgen stimulation, these data support an AR-ERG-HES1-HES6 transcriptional network in $E R G$-fusion positive prostate cancer cells. While in ERG-fusion negative cells, a simpler AR-HES6 network seems to occur. In each case, these transcriptional networks may have been preceded (and potentiated) by HES5 epigenetic silencing in early tumourigenesis.

\section{Discussion}

Our data are consistent with an early role in prostate tumourigenesis for promoter-wide hypermethylation of HES5, supported by the very high frequency of this epigenetic change and our observation that this was a common alteration in a series of multi-focal tumours. While the functional role of HES5 methylation in prostate tumourigenesis is yet to be determined, we found that demethylation resulted in downregulation of the HES5target gene HES6, which has recently been shown to drive

Published by Bioscientifica Ltd. 
progression in prostate cancer via the androgen receptor (Ramos-Montoya et al. 2014). Therefore, we speculate that one potential effector mechanism of HES5 silencing could be de-repression of HES6 that in turn enhances $\mathrm{AR}$ regulation of key oncogenic targets, contributing to transformation and/or priming cells for subsequent acquisition of aggressive phenotypes. In addition, HES5 has established roles in tissue patterning during development (Hatakeyama et al. 2004, Tateya et al. 2011), with HES5-null cells promoting an imbalance in intestinal and neural stem cell fate choices resulting from defective NOTCH signalling (Sancho et al. 2013). Intriguingly defective NOTCH signalling has recently been shown to drive clonal expansions of P53 mutant cells (Alcolea et al. 2014), raising the possibility that HES5 silencing early in prostate tumourogenesis might drive clonal expansions and contribute to the 'field effect' observed in prostate tumours (Bostwick et al. 1998, Hanson et al. 2006, Mehrotra et al. 2008). However, these and other downstream consequences of the early and common epigenetic silencing of HES5 will require careful dissection in future studies.

It is intriguing that this HES5-HES6/AR-HES6 transcriptional network is affected by TMPRSS2-ERG gene fusion status. While the functional consequences of this remain to be explored, the implication of both $A R$ and $E R G$ oncogenenic signalling axes provides further weight for the importance of the HES transcriptional network in prostate cancer. Future studies will need to include overexpression of HES5 in prostate cancer cells to establish the direct consequences on HES6 and AR signalling, as well as the phenotypic consequences of bypassing HES5 silencing. In addition, depletion of HES5 in 5-aza2 '-deoxycytidine-treated prostate cancer cells (both ERGpositive and $E R G$-negative) will allow an assessment of de-repression of the endogenous HES5 locus on gene expression and cellular phenotypes. Finally, future studies should also address the mechanisms upstream of HES5 silencing, the high frequency of which would be consistent with either a strong-selective pressure or a targeted silencing of HES5, for example via loss of GCM as described in neural stem cells (Hitoshi et al. 2011).

This report highlights HES5 silencing as an early and frequent event in prostate tumourigenesis that may serve as a useful biomarker or as a starting point for preventive medicine or targeted intervention strategies.

\section{Supplementary data}

This is linked to the online version of the paper at http://dx.doi.org/10.1530/ ERC-14-0454.
Declaration of interest

The authors declare that there is no conflict of interest that could be perceived as prejudicing the impartiality of the research reported.

\section{Funding}

The ICGC Prostate UK Group is funded by Cancer Research UK Grant C5047/A14835, by the Dallaglio Foundation, and by The Wellcome Trust. The Human Research Tissue Bank is supported by the NIHR Cambridge Biomedical Research Centre.

\section{Author contribution statement}

C E Massie carried out analysis, directed the project and wrote the manuscript; I Spiteri designed and carried out bisulphite sequencing experiments; $H$ Ross-Adams prepared samples for bisulphite sequencing and tumour gene expression data; $\mathrm{H}$ Luxton, J Kay and $\mathrm{H} \mathrm{C}$ Whitaker co-designed and provided all samples for the initial methylation profiling, expression and validation experiments; M J Dunning, A D Lamb and A Ramos-Montoya provided tumour gene expression data; A Y Warren carried out systematic pathology of prostatectomy samples and identified tumour and benign cores for sampling; $S$ Tavaré designed the study and drafted the manuscript; D S Brewer, C S Cooper, R Eeles and the ICGC Working Group provided 3D prostate reconstructions, contributed to study design and drafted the manuscript; D E Neal co-designed the study and drafted the manuscript; A G Lynch co-designed the study, carried out analysis, directed the project and co-authored the manuscript.

\section{Acknowledgements}

The authors are grateful to study volunteers for their participation and staff at the Welcome Trust Clinical Research Facility, Addenbrooke's Clinical Research Centre, Cambridge. They also thank the NIHR Cambridge Biomedical Research Centre, the DOH HTA (ProtecT grant), and the NCRI/MRC (ProMPT grant) for help with the bio-repository, The University of Cambridge, Hutchison Whampoa Limited and Cancer Research UK for funding. They are grateful to the CRUK Cambridge Institute Genomics and Bioinformatics Core Facilities. Cross-validation of HES5 methylation includes the use of data generated by the TCGA Research Network: http://cancergenome.nih.gov/.

\section{References}

Alcolea MP, Greulich P, Wabik A, Frede J, Simons BD \& Jones PH 2014 Differentiation imbalance in single oesophageal progenitor cells causes clonal immortalization and field change. Nature Cell Biology 16 615-622. (doi:10.1038/ncb2963)

Annala M, Kivinummi K, Leinonen K, Tuominen J, Zhang W, Visakorpi T \& Nykter M 2014 DOT1L-HES6 fusion drives androgen independent growth in prostate cancer. EMBO Molecular Medicine 6 1121-1123. (doi:10.15252/emmm.201404210)

Aryee MJ, Jaffe AE, Corrada-Bravo H, Ladd-Acosta C, Feinberg AP, Hansen KD \& Irizarry RA 2014 Minfi: a flexible and comprehensive Bioconductor package for the analysis of Infinium DNA methylation microarrays. Bioinformatics 30 1363-1369. (doi:10.1093/bioinformatics/btu049)

Austin DW, Allen MS, McCollum JM, Dar RD, Wilgus JR, Sayler GS, Samatova NF, Cox CD \& Simpson ML 2006 Gene network shaping of inherent noise spectra. Nature 439 608-611. (doi:10.1038/ nature04194)

Published by Bioscientifica Ltd. 
Baca SC, Prandi D, Lawrence MS, Mosquera JM, Romanel A, Drier Y, Park K, Kitabayashi N, MacDonald TY, Ghandi M et al. 2013 Punctuated evolution of prostate cancer genomes. Cell 153 666-677. (doi:10.1016/ j.cell.2013.03.021)

Bae S, Bessho Y, Hojo M \& Kageyama R 2000 The bHLH gene Hes6, an inhibitor of Hes1, promotes neuronal differentiation. Development 127 2933-2943.

Barbieri CE, Baca SC, Lawrence MS, Demichelis F, Blattner M, Theurillat JP, White TA, Stojanov P, Van Allen E, Stransky N et al. 2012 Exome sequencing identifies recurrent SPOP, FOXA1 and MED12 mutations in prostate cancer. Nature Genetics 44 685-689. (doi:10.1038/ng.2279)

Barry M, Perner S, Demichelis F \& Rubin MA 2007 TMPRSS2-ERG fusion heterogeneity in multifocal prostate cancer: clinical and biologic implications. Urology 70 630-633. (doi:10.1016/j.urology.2007.08.032)

Berger MF, Lawrence MS, Demichelis F, Drier Y, Cibulskis K, Sivachenko AY, Sboner A, Esgueva R, Pflueger D, Sougnez C et al. 2011 The genomic complexity of primary human prostate cancer. Nature $\mathbf{4 7 0} 214-220$. (doi:10.1038/nature09744)

Biankin AV, Waddell N, Kassahn KS, Gingras MC, Muthuswamy LB, Johns AL, Miller DK, Wilson PJ, Patch AM, Wu J et al. 2012 Pancreatic cancer genomes reveal aberrations in axon guidance pathway genes. Nature 491 399-405. (doi:10.1038/nature11547)

Bolton EC, So AY, Chaivorapol C, Haqq CM, Li H \& Yamamoto KR 2007 Cell- and gene-specific regulation of primary target genes by the androgen receptor. Genes and Development 21 2005-2017. (doi:10.1101/ gad.1564207)

Bostwick DG, Shan A, Qian J, Darson M, Maihle NJ, Jenkins RB \& Cheng L 1998 Independent origin of multiple foci of prostatic intraepithelial neoplasia: comparison with matched foci of prostate carcinoma. Cancer 83 1995-2002. (doi:10.1002/(SICI)1097-0142(19981101)83:9<1995 ::AID-CNCR16>3.0.CO;2-2)

Caini S, Gandini S, Dudas M, Bremer V, Severi E \& Gherasim A 2014 Sexually transmitted infections and prostate cancer risk: a systematic review and meta-analysis. Cancer Epidemiology 38 329-338. (doi:10.1016/j.canep.2014.06.002)

Cairns JM, Dunning MJ, Ritchie ME, Russell R \& Lynch AG 2008 BASH: a tool for managing BeadArray spatial artefacts. Bioinformatics 24 2921-2922. (doi:10.1093/bioinformatics/btn557)

Cancer Genome Atlas Network 2012 Comprehensive molecular characterization of human colon and rectal cancer. Nature $\mathbf{4 8 7}$ 330-337. (doi:10.1038/nature11252)

Cancer Genome Atlas Research Network 2011 Integrated genomic analyses of ovarian carcinoma. Nature 474 609-615. (doi:10.1038/nature10166)

Carver BS, Tran J, Gopalan A, Chen Z, Shaikh S, Carracedo A, Alimonti A, Nardella C, Varmeh S, Scardino PT et al. 2009 Aberrant ERG expression cooperates with loss of PTEN to promote cancer progression in the prostate. Nature Genetics 41 619-624. (doi:10.1038/ng.370)

Chen Y, Chi P, Rockowitz S, Iaquinta PJ, Shamu T, Shukla S, Gao D, Sirota I, Carver BS, Wongvipat J et al. 2013 ETS factors reprogram the androgen receptor cistrome and prime prostate tumorigenesis in response to PTEN loss. Nature Medicine 19 1023-1029. (doi:10.1038/nm.3216)

Davis S \& Meltzer PS 2007 GEOquery: a bridge between the Gene Expression Omnibus (GEO) and BioConductor. Bioinformatics 23 1846-1847. (doi:10.1093/bioinformatics/btm254)

Dunning MJ, Smith ML, Ritchie ME \& Tavare S 2007 beadarray: R classes and methods for Illumina bead-based data. Bioinformatics 23 2183-2184. (doi:10.1093/bioinformatics/btm311)

Eeles RA, Olama AA, Benlloch S, Saunders EJ, Leongamornlert DA, Tymrakiewicz M, Ghoussaini M, Luccarini C, Dennis J, JugurnauthLittle S et al. 2013 Identification of 23 new prostate cancer susceptibility loci using the iCOGS custom genotyping array. Nature Genetics $\mathbf{4 5}$ 385-391. 391e381-382. (doi:10.1038/ng.2560)

Elkahwaji JE, Hauke RJ \& Brawner CM 2009 Chronic bacterial inflammation induces prostatic intraepithelial neoplasia in mouse prostate. British Journal of Cancer 101 1740-1748. (doi:10.1038/sj.bjc.6605370)
Fior R \& Henrique D 2005 A novel hes5/hes6 circuitry of negative regulation controls Notch activity during neurogenesis. Developmental Biology 281 318-333. (doi:10.1016/j.ydbio.2005.03.017)

Freedland SJ 2005 Obesity and prostate cancer: a growing problem. Clinical Cancer Research 11 6763-6766. (doi:10.1158/1078-0432.CCR-05-1305)

Garcia AJ, Ruscetti M, Arenzana TL, Tran LM, Bianci-Frias D, Sybert E, Priceman SJ, Wu L, Nelson PS, Smale ST et al. 2014 Pten null prostate epithelium promotes localized myeloid-derived suppressor cell expansion and immune suppression during tumor initiation and progression. Molecular and Cellular Biology 34 2017-2028. (doi:10.1128/ MCB.00090-14)

Grasso CS, Wu YM, Robinson DR, Cao X, Dhanasekaran SM, Khan AP, Quist MJ, Jing X, Lonigro RJ, Brenner JC et al. 2012 The mutational landscape of lethal castration-resistant prostate cancer. Nature $\mathbf{4 8 7}$ 239-243. (doi:10.1038/nature11125)

Hanson JA, Gillespie JW, Grover A, Tangrea MA, Chuaqui RF, Emmert-Buck MR, Tangrea JA, Libutti SK, Linehan WM \& Woodson KG 2006 Gene promoter methylation in prostate tumor-associated stromal cells. Journal of the National Cancer Institute 98 255-261. (doi:10.1093/jnci/djj051)

Hatakeyama J, Bessho Y, Katoh K, Ookawara S, Fujioka M, Guillemot F \& Kageyama R 2004 Hes genes regulate size, shape and histogenesis of the nervous system by control of the timing of neural stem cell differentiation. Development 131 5539-5550. (doi:10.1242/dev.01436)

Hatakeyama J, Sakamoto S \& Kageyama R 2006 Hes1 and Hes5 regulate the development of the cranial and spinal nerve systems. Developmental Neuroscience 28 92-101. (doi:10.1159/000090756)

Heaphy CM, Yoon GS, Peskoe SB, Joshu CE, Lee TK, Giovannucci E, Mucci LA, Kenfield SA, Stampfer MJ, Hicks JL et al. 2013 Prostate cancer cell telomere length variability and stromal cell telomere length as prognostic markers for metastasis and death. Cancer Discovery 3 1130-1141. (doi:10.1158/2159-8290.CD-13-0135)

Hitoshi S, Ishino Y, Kumar A, Jasmine S, Tanaka KF, Kondo T, Kato S, Hosoya T, Hotta Y \& Ikenaka K 2011 Mammalian Gcm genes induce Hes5 expression by active DNA demethylation and induce neural stem cells. Nature Neuroscience 14 957-964. (doi:10.1038/nn.2875)

Jacobsen KX, Vanderluit JL, Slack RS \& Albert PR 2008 HES1 regulates 5-HT1A receptor gene transcription at a functional polymorphism: essential role in developmental expression. Molecular and Cellular Neurosciences 38 349-358. (doi:10.1016/j.mcn.2008.03.007)

Jia L, Berman BP, Jariwala U, Yan X, Cogan JP, Walters A, Chen T, Buchanan G, Frenkel B \& Coetzee GA 2008 Genomic androgen receptor-occupied regions with different functions, defined by histone acetylation, coregulators and transcriptional capacity. PLOS ONE 3 e3645. (doi:10.1371/journal.pone.0003645)

Kalaany NY \& Sabatini DM 2009 Tumours with PI3K activation are resistant to dietary restriction. Nature 458 725-731. (doi:10.1038/nature07782)

Kanwal R, Pandey M, Bhaskaran N, Maclennan GT, Fu P, Ponsky LE \& Gupta S 2014 Protection against oxidative DNA damage and stress in human prostate by glutathione S-transferase P1. Molecular Carcinogenesis 53 8-18. (doi:10.1002/mc.21939)

Kote-Jarai Z, Olama AA, Giles GG, Severi G, Schleutker J, Weischer M, Campa D, Riboli E, Key T, Gronberg H et al. 2011 Seven prostate cancer susceptibility loci identified by a multi-stage genome-wide association study. Nature Genetics 43 785-791. (doi:10.1038/ng.882)

Krueger F \& Andrews SR 2011 Bismark: a flexible aligner and methylation caller for Bisulfite-Seq applications. Bioinformatics 27 1571-1572. (doi:10.1093/bioinformatics/btr167)

Kwon OJ, Zhang L, Ittmann MM \& Xin L 2014 Prostatic inflammation enhances basal-to-luminal differentiation and accelerates initiation of prostate cancer with a basal cell origin. PNAS 111 E592-E600. (doi:10.1073/pnas.1318157111)

Lee WH, Morton RA, Epstein JI, Brooks JD, Campbell PA, Bova GS, Hsieh WS, Isaacs WB \& Nelson WG 1994 Cytidine methylation of regulatory sequences near the pi-class glutathione S-transferase gene accompanies human prostatic carcinogenesis. PNAS 91 11733-11737. (doi:10.1073/ pnas.91.24.11733) 
Lin B, Wang J, Hong X, Yan X, Hwang D, Cho JH, Yi D, Utleg AG, Fang X, Schones DE et al. 2009 Integrated expression profiling and ChIP-seq analyses of the growth inhibition response program of the androgen receptor. PLoS ONE 4 e6589. (doi:10.1371/journal.pone.0006589)

Lindberg J, Klevebring D, Liu W, Neiman M, Xu J, Wiklund P, Wiklund F, Mills IG, Egevad L \& Gronberg H 2013 Exome sequencing of prostate cancer supports the hypothesis of independent tumour origins. European Urology 63 347-353. (doi:10.1016/j.eururo.2012.03.050)

Longabaugh WJ 2012 BioTapestry: a tool to visualize the dynamic properties of gene regulatory networks. Methods in Molecular Biology 786 359-394. (doi:10.1007/978-1-61779-292-2_21)

Marabita F, Almgren M, Lindholm ME, Ruhrmann S, Fagerstrom-Billai F, Jagodic M, Sundberg CJ, Ekstrom TJ, Teschendorff AE, Tegner J et al. 2013 An evaluation of analysis pipelines for DNA methylation profiling using the Illumina HumanMethylation450 BeadChip platform. Epigenetics 8 333-346. (doi:10.4161/epi.24008)

Massie CE, Adryan B, Barbosa-Morais NL, Lynch AG, Tran MG, Neal DE \& Mills IG 2007 New androgen receptor genomic targets show an interaction with the ETS1 transcription factor. EMBO Reproduction $\mathbf{8}$ 871-878. (doi:10.1038/sj.embor.7401046)

Massie CE, Lynch A, Ramos-Montoya A, Boren J, Stark R, Fazli L, Warren A, Scott H, Madhu B, Sharma N et al. 2011 The androgen receptor fuels prostate cancer by regulating central metabolism and biosynthesis. EMBO Journal 30 2719-2733. (doi:10.1038/emboj.2011.158)

Mehrotra J, Varde S, Wang H, Chiu H, Vargo J, Gray K, Nagle RB, Neri JR \& Mazumder A 2008 Quantitative, spatial resolution of the epigenetic field effect in prostate cancer. Prostate 68 152-160. (doi:10.1002/ pros.20675)

Mertz KD, Horcic M, Hailemariam S, D'Antonio A, Dirnhofer S, Hartmann A, Agaimy A, Eppenberger-Castori S, Obermann E, Cathomas G et al. 2013 Heterogeneity of ERG expression in core needle biopsies of patients with early prostate cancer. Human Pathology 44 2727-2735. (doi:10.1016/j.humpath.2013.07.019)

Minner S, Gartner M, Freudenthaler F, Bauer M, Kluth M, Salomon G, Heinzer H, Graefen M, Bokemeyer C, Simon R et al. 2013 Marked heterogeneity of ERG expression in large primary prostate cancers. Modern Pathology 26 106-116. (doi:10.1038/modpathol.2012.130)

Mounir Z, Lin F, Lin VG, Korn JM, Yu Y, Valdez R, Aina OH, Buchwalter G, Jaffe AB, Korpal M et al. 2014 TMPRSS2:ERG blocks neuroendocrine and luminal cell differentiation to maintain prostate cancer proliferation. Oncogene [in press]. (doi:10.1038/onc.2014.308)

Nevozhay D, Adams RM, Murphy KF, Josic K \& Balazsi G 2009 Negative autoregulation linearizes the dose-response and suppresses the heterogeneity of gene expression. PNAS 106 5123-5128. (doi:10.1073/ pnas.0809901106)

Nik-Zainal S, Van Loo P, Wedge DC, Alexandrov LB, Greenman CD, Lau KW, Raine K, Jones D, Marshall J, Ramakrishna M et al. 2012 The life history of 21 breast cancers. Cell 149 994-1007. (doi:10.1016/j.cell.2012.04.023)

Paziewska A, Dabrowska M, Goryca K, Antoniewicz A, Dobruch J, Mikula M, Jarosz D, Zapala L, Borowka A \& Ostrowski J 2014 DNA methylation status is more reliable than gene expression at detecting cancer in prostate biopsy. British Journal of Cancer 111 781-789. (doi:10.1038/ bjc.2014.337)

Perner S, Demichelis F, Beroukhim R, Schmidt FH, Mosquera JM, Setlur S, Tchinda J, Tomlins SA, Hofer MD, Pienta KG et al. 2006 TMPRSS2:ERG fusion-associated deletions provide insight into the heterogeneity of prostate cancer. Cancer Research 66 8337-8341. (doi:10.1158/00085472.CAN-06-1482)

Pollock RF \& Adryan B 2008 BioSAVE: display of scored annotation within a sequence context. BMC Bioinformatics 9 157. (doi:10.1186/ 1471-2105-9-157)

Ramos-Montoya A, Lamb AD, Russell R, Carroll T, Jurmeister S, GaleanoDalmau N, Massie CE, Boren J, Bon H, Theodorou V et al. 2014 HES6 drives a critical AR transcriptional programme to induce castrationresistant prostate cancer through activation of an E2F1-mediated cell cycle network. EMBO Molecular Medicine 6 651-661. (doi:10.1002/ emmm.201303581)

R-Core-Team 2014 R: A Language and Environment for Statistical Computing. Vienna, Austria: R Foundation for Statistical Computing.

Rosenfeld N, Elowitz MB \& Alon U 2002 Negative autoregulation speeds the response times of transcription networks. Journal of Molecular Biology 323 785-793. (doi:10.1016/S0022-2836(02)00994-4)

Salama-Cohen P, Arevalo MA, Meier J, Grantyn R \& Rodriguez-Tebar A 2005 NGF controls dendrite development in hippocampal neurons by binding to p75NTR and modulating the cellular targets of Notch. Molecular Biology of the Cell 16 339-347. (doi:10.1091/mbc. E04-05-0438)

Sancho R, Blake SM, Tendeng C, Clurman BE, Lewis J \& Behrens A 2013 Fbw7 repression by hes 5 creates a feedback loop that modulates Notchmediated intestinal and neural stem cell fate decisions. PLoS Biology 11 e1001586. (doi:10.1371/journal.pbio.1001586)

Sharma NL, Massie CE, Ramos-Montoya A, Zecchini V, Scott HE, Lamb AD, MacArthur S, Stark R, Warren AY, Mills IG et al. 2013 The androgen receptor induces a distinct transcriptional program in castrationresistant prostate cancer in man. Cancer Cell 23 35-47. (doi:10.1016/ j.ccr.2012.11.010)

Shen-Orr SS, Milo R, Mangan S \& Alon U 2002 Network motifs in the transcriptional regulation network of Escherichia coli. Nature Genetics $\mathbf{3 1}$ 64-68. (doi:10.1038/ng881)

Sommerfeld HJ, Meeker AK, Piatyszek MA, Bova GS, Shay JW \& Coffey DS 1996 Telomerase activity: a prevalent marker of malignant human prostate tissue. Cancer Research 56 218-222.

Statham AL, Robinson MD, Song JZ, Coolen MW, Stirzaker C \& Clark SJ 2012 Bisulfite sequencing of chromatin immunoprecipitated DNA (BisChIP-seq) directly informs methylation status of histone-modified DNA. Genome Research 22 1120-1127. (doi:10.1101/gr.132076.111)

Takayama K, Kaneshiro K, Tsutsumi S, Horie-Inoue K, Ikeda K, Urano T, Ijichi N, Ouchi Y, Shirahige K, Aburatani H et al. 2007 Identification of novel androgen response genes in prostate cancer cells by coupling chromatin immunoprecipitation and genomic microarray analysis. Oncogene 26 4453-4463. (doi:10.1038/sj.onc.1210229)

Tarpey PS, Behjati S, Cooke SL, Van Loo P, Wedge DC, Pillay N, Marshall J, O'Meara S, Davies H, Nik-Zainal S et al. 2013 Frequent mutation of the major cartilage collagen gene COL2A1 in chondrosarcoma. Nature Genetics 45 923-926. (doi:10.1038/ng.2668)

Tateya T, Imayoshi I, Tateya I, Ito J \& Kageyama R 2011 Cooperative functions of Hes/Hey genes in auditory hair cell and supporting cell development. Developmental Biology 352 329-340. (doi:10.1016/ j.ydbio.2011.01.038)

Tomlins SA, Rhodes DR, Perner S, Dhanasekaran SM, Mehra R, Sun XW, Varambally S, Cao X, Tchinda J, Kuefer R et al. 2005 Recurrent fusion of TMPRSS2 and ETS transcription factor genes in prostate cancer. Science 310 644-648. (doi:10.1126/science.1117679)

Turatsinze JV, Thomas-Chollier M, Defrance M \& van Helden J 2008 Using RSAT to scan genome sequences for transcription factor binding sites and cis-regulatory modules. Nature Protocols 3 1578-1588. (doi:10.1038/nprot.2008.97)

Varley KE, Gertz J, Bowling KM, Parker SL, Reddy TE, Pauli-Behn F, Cross MK, Williams BA, Stamatoyannopoulos JA, Crawford GE et al. 2013 Dynamic DNA methylation across diverse human cell lines and tissues. Genome Research 23 555-567. (doi:10.1101/gr.147942.112)

Wang Q, Li W, Liu XS, Carroll JS, Jänne OA, Keeton EK, Chinnaiyan AM, Pienta KJ \& Brown M 2007 A hierarchical network of transcription factors governs androgen receptor-dependent prostate cancer growth. Molecular Cell 27 380-392. (doi:10.1016/j.molcel.2007.05.041)

Wang Q, Li W, Zhang Y, Yuan X, Xu K, Yu J, Chen Z, Beroukhim R, Wang H, Lupien $\mathrm{M}$ et al. 2009 Androgen receptor regulates a distinct transcription program in androgen-independent prostate cancer. Cell 138 245-256. (doi:10.1016/j.cell.2009.04.056)

Warren AY, Whitaker HC, Haynes B, Sangan T, McDuffus LA, Kay JD \& Neal DE 2013 Method for sampling tissue for research which preserves

Published by Bioscientifica Ltd 
pathological data in radical prostatectomy. Prostate 73 194-202. (doi:10.1002/pros.22556)

Weaver JM, Ross-Innes CS, Shannon N, Lynch AG, Forshew T, Barbera M, Murtaza M, Ong CA, Lao-Sirieix P, Dunning MJ et al. 2014 Ordering of mutations in preinvasive disease stages of esophageal carcinogenesis. Nature Genetics 46 837-843. (doi:10.1038/ng.3013)

Wei GH, Badis G, Berger MF, Kivioja T, Palin K, Enge M, Bonke M, Jolma A, Varjosalo M, Gehrke AR et al. 2010 Genome-wide analysis of ETS-family DNA-binding in vitro and in vivo. EMBO Journal 29 2147-2160. (doi:10.1038/emboj.2010.106)

Weinstein JN, Collisson EA, Mills GB, Shaw KR, Ozenberger BA, Ellrott K, Shmulevich I, Sander C \& Stuart JM 2013 The Cancer Genome Atlas Pan-Cancer analysis project. Nature Genetics 45 1113-1120. (doi:10.1038/ng.2764)
Weischenfeldt J, Simon R, Feuerbach L, Schlangen K, Weichenhan D, Minner S, Wuttig D, Warnatz HJ, Stehr H, Rausch T et al. 2013 Integrative genomic analyses reveal an androgen-driven somatic alteration landscape in early-onset prostate cancer. Cancer Cell $\mathbf{2 3}$ 159-170. (doi:10.1016/j.ccr.2013.01.002)

Yan J, Enge M, Whitington T, Dave K, Liu J, Sur I, Schmierer B, Jolma A, Kivioja T, Taipale M et al. 2013 Transcription factor binding in human cells occurs in dense clusters formed around cohesin anchor sites. Cell 154 801-813. (doi:10.1016/j.cell.2013. 07.034)

Yu J, Yu J, Mani RS, Cao Q, Brenner CJ, Cao X, Wang X, Wu L, Li J, Hu M et al. 2010 An integrated network of androgen receptor, polycomb, and TMPRSS2-ERG gene fusions in prostate cancer progression. Cancer Cell 17 443-454. (doi:10.1016/j.ccr.2010.03.018)

Received in final form 18 December 2014

Accepted 5 January 2015

Made available online as an Accepted Preprint

5 January 2015
Published by Bioscientifica Ltd. 